\title{
An Investigation of Canadian Undergraduate Music Education Students' Personal and Professional Experiences During a Three-Month Residency in China
}

\author{
Jonathan G. Bayley \\ University of Windsor \\ Vanessa A. Mio \\ University of Windsor
}

\begin{abstract}
The present study investigated undergraduate Canadian music education students' personal and professional experiences during a three-month residency in China. Participants $(N=3)$, in this case study, were part of a SSHRC funded Canada-China Reciprocal Learning Program and were in the process of completing a Bachelor of Education degree. The participants observed classroom teaching, attended workshops/presentations at Southwest University in Chongqing, China, and gave presentations to Chinese teachers and students. They were asked a wide range of open-ended questions relating to their preconceptions of life in China, coping strategies (e.g., language, local customs, environmental context, etc.), curricular and pedagogical similarities/differences, relationships with their Chinese counterparts, and potential impact on their future educational and professional plans. The findings indicated intellectual, social, and personal growth over this three-month period. Students spoke of overcoming fear and acquiring increased personal/professional self-awareness. However, there was no solid assurance that the participants' experiences would have a lasting positive effect on their future pedagogical practices.
\end{abstract}

Editor's note: An abbreviation of this article was originally accepted and published in the Proceedings of the International Society of Music Education (ISME) 34th World Conference, 2020. The full article is published here with permissions from the ISME Executive Board (May 5, 2020). 


\section{Introduction}

Canada has had an ongoing relationship with the People's Republic of China for over a half century, resulting in strong bilateral cooperation. According to the Government of Canada website:

Canada's relationship with China is long-standing and dates from well before the establishment of diplomatic relations in $1970 \ldots$. [The Canadian government works] with China at the federal, provincial, territorial and municipal levels. Areas of engagement include trade and investment, environment and climate change, law enforcement, education and culture, and consular affairs. (Government of Canada, 2019)

It is not by accident that close ties with China continue to grow. Canada's population demographics make clear the importance of this cultural group:

Strong people-to-people ties link Canada and China: over 1.8 million Canadian residents are of Chinese origin, and in 2018, more than 140,000 Chinese students attended Canadian educational institutions. Chinese is Canada's third most spoken language after English and French, and immigrants born in China (including the Hong Kong Special Administrative Region) form one of the largest groups within Canada's immigrant population. (Government of Canada, 2019)

Preservice students from the University of Windsor were given the opportunity to travel to China for a period of three months. During this time, they observed the teaching of elementary and secondary subjects in Chongqing, China, attended workshops and presentations at Southwest University, taught mini-lessons and gave presentations in the presence of Chinese students and teachers. While in China, each Canadian student was assigned a Chinese 'buddy;' a Southwest University undergraduate education student who had previously completed a three-month residency in Canada at the University of Windsor.

The [Chinese] buddies were all picked on the basis of their English language skills and their academic excellence, as well as their intention to travel to Canada with the exchange program. The support of the buddies was paramount to the security and enjoyment as well as the learning of the Canadian students. (Sefton, Rideout, \& Bayley, 2016, p. 5)

In essence, they were the Canadian students' Chinese friends who were close to completing their education degrees. In additional to the professional and academic opportunities that were available to the Canadian preservice teachers as a result of this exchange, they also spent a considerable amount of time socializing with their Chinese counterparts, especially in the evenings.

These cultural and educational exchanges have come about in large part because of the Canada-China Partnership Grant Project. This is a seven-year collaboration involving "four Canadian and four Chinese postsecondary partner institutions and is funded by the Social Sciences and Humanities Research Council of Canada" (Xu \& Connelly, 2017, p. 136). Xu and Connelly (2017) state that "the partnership's overall goal is to compare and contrast Canadian and Chinese education in such a way that the educational narratives of each provide frameworks for understanding and appreciating educational similarities and differences" (p. 137). The purpose of this study was to investigate Canadian undergraduate music education students' personal and professional experiences during a three-month residency in China. Findings may assist program 
directors in their decision-making when organizing future intercultural exchanges and provide valuable insight for students who might consider participating in such a venture.

\section{Review of the Literature}

Through the lens of social constructivism, learning does not occur in isolation, but through shared experiences of collaboration and dialogue (Charmaz, 2006; Powell, 2006; Powell \& Kalina, 2009; Vygotsky, 1978). In addition to the reciprocal dialogue and collaborative expectations within the professional school setting, preservice teachers should also acquire a "culturally responsive stance and awareness...ensuring a richer and more authentic depiction of the various cultures around [them]" (Zhao, Meyers, \& Meyers, 2009, p. 296). Current research suggests that "a teacher preparation curriculum that emphasizes teacher candidates' expansion of worldviews through exposure to diversity will enable them to incorporate global and intercultural perspectives into their classroom" (Dunn, Dotson, Cross, Kesner, \& Lundahl, 2014, p. 285). Although this is possible to develop in traditional elementary field placements, study abroad programs "present more robust portraits of teaching" (Ladson-Billings, 1995, p. 484) for preservice teachers in the field, as they not only learn "about others, but also...from and with others" (Zhao et al., 2009, p. $313)$.

Norris and Gillespie (2009) determined that there is a significant impact on the career paths of students who study abroad, including their continued use of foreign language and future global work. In a similar fashion, Cushner (2007) concluded that preservice teachers who have the opportunity to study abroad emerge as unique professionals with an international vantage point of socialization that cannot be replicated in domestic teaching experiences. Stachowski, Richardson, and Henderson (2003) studied the effects of cultural values on 88 preservice teachers involved in a study abroad program and determined that they developed increased cultural awareness and sensitivity in their professional growth as individuals. In a similar fashion, Brindley, Quinn, and Morton (2008) noted improvements in professional development, knowledge of community, classroom management, responsibility, communication with children, and comprehension of broad curricular expectations. According to Willard-Holt (2001), "the greatest benefits [of studying abroad include] growth of tolerance, acceptance of self and others, and independence" (p, 506). These research studies have the potential to impact Western preservice teachers' instructional practices, self-efficacy, and teaching competence as they develop into globally minded future educators (Malewski \& Phillion, 2009; Marx \& Moss, 2011; Pence \& Macgillivray, 2008; Zhao, 2007).

Although there are many professional and personal benefits for preservice teachers while studying abroad, challenges and opportunities for growth may arise throughout the process. Western preservice teachers who study abroad in Asian countries have the added challenges of language barriers and ethnic and cultural expectations, which often lead to feelings of insecurity and being inadequately prepared in the classroom (Gay, 2002; Merryfield, 2000; Zhao et al., 2009). In a study conducted by Zhao et al. (2009), researchers investigated 10 Western elementary preservice teachers' experiences before and after living in China for four weeks. They determined that although the participants yielded positive responses to the cross-cultural immersion and believed the experience impacted their future teaching careers, they faced many challenges with the language and culture, in addition to homesickness (Pence \& Macgillivray, 2008; Sahin, 2008; Trilokekar \& Kukar, 2011; Zhao et al., 2009).

To alleviate some of these inevitable challenges, researchers suggest that preservice teachers acquire a "culturally responsive pedagogical stance...to better understand their students' 
cultures and to teach through their own cultural and experiential filters" (Zhao et al., 2009, p. 297). To aid in this regard, Faulconer (2003) documented the importance of observation within various educational systems as a means to challenge the potential prejudices that may arise in preservice teachers while studying abroad. In a similar fashion, researchers have studied the benefits of ongoing critical reflection throughout the study abroad process as a means for preservice teachers to record their lived experiences (Cushner \& Mahon, 2002; Stachowski \& Sparks, 2007). Robertson and Webber (2000) contend that extensive field notes, reflective journals, and opportunities for dialogue are an essential part of the international experience, in addition to "collegial dialogue and participant bonding" (p. 327) through socializing and sightseeing. Through shared lived experiences and reflective practices, preservice teachers increase their potential ability to cope with the inevitable cultural challenges and acquire an understanding of how culture ultimately impacts learning (Kabilan, 2013; Marx \& Moss, 2011; Phillion, Malewski, Sharma, \& Wang, 2009; Volet \& Ang, 2012). In essence, "overseas student teaching can serve as the catalyst that starts teachers on a path of learning from others: their students, their colleagues, their community, and their world" (Cushner \& Mahon, 2002, p. 56), creating future educators who possess a global perspective in the professional field.

More specifically, as students engage in cross-cultural teaching experiences, reciprocal learning is an inevitable result. Reciprocal learning involves "learning from and with each other in both formal and informal ways. It includes mutual benefits and a sharing of knowledge, ideas, and experience among [individuals]" (Boud, 1999, p. 4) in order to "construct meaning and knowledge together in community" (Lambert, 2002, p. xvii). As a result, individuals have the potential to learn more than they could on their own, as they engage in metacognitive practices, dialogue, and teamwork (Hoy \& Miskel, 2005; Van Swet \& Ponte, 2007). While studying abroad, preservice teachers often experience feelings of inadequacy, vulnerability, and low self-efficacy as they strive to establish and develop their professional identity and pedagogical skills in a foreign land (Jones, 2005). Although these challenges are inevitable, reciprocal learning opportunities encourage preservice teachers to discuss their practice, observe one another, problem solve current professional challenges, and converse about issues they may be facing in the classroom (Biddle, 2010). Through this collaborative, supportive environment, preservice teachers enter into a giveand-take learning relationship with their colleagues, where they are not only thinking of their own professional growth but the growth of others (Biddle, 2010).

Although researchers have conducted studies pertaining to the effects of language acquisition, cultural awareness, support when returning home, institutional and personal barriers, and the psychosocial development of preservice teachers, there is a lack of research pertaining to the academic and psychological challenges of Western preservice teachers studying in Asian countries through reciprocal learning programs (Carson \& Longhini, 2002; Dessoff, 2006; Kabilan, 2013; Mendelson \& Citron, 2006; Nieto, 2006; Norris \& Dwyer, 2005; Sahin, 2008; Segalowitz \& Freed, 2004; Thomas, 2006). The following research question was used to guide this study: what were Canadian preservice music education students' perceived personal and professional lived experiences during a three-month residency in China?

\section{Methodology}

A case study research design was chosen for this study. According to Creswell (2013), case study research could explore the following: 
[A] real-life, contemporary bounded system (a case) or multiple bounded systems (cases) over time, through detailed, in-depth data collection involving multiple sources of information (e.g., observations, interviews, audiovisual material, and documents and reports), and reports a case description and case themes. (p. 97)

This research presents a multiple or collective case study, which is defined as "a number of cases studied jointly in order to investigate a phenomenon, population, or general condition" (Stake, 2005, p. 445), where the "inquirer purposefully selects multiple cases to show different perspectives on the issue" (Creswell, 2013, p. 99). The conceptual framework for this study draws upon the literature relating to international education, study-abroad programs, and reciprocal learning in teacher education.

\section{Participants}

The Canadian research participants $(N=3)$ were in the process of completing their Bachelor of Education degree and had previously completed a Bachelor of Arts (Music) or a Bachelor of Music degree from a Canadian university. As a result, they were in a position to provide their insights regarding the music education they witnessed in China. The participants for this case study included two males and one female; two Asian and one Caucasian (all Canadian). The following is a brief description of the participants' backgrounds: Cello was born in Malaysia and arrived in Canada when she was a very young child. She admitted to having difficulty adjusting to the Chinese context, which she described as "superficial." Bryce viewed China as "a bit of a playground," as this was his first trip outside of North America. As a young child, Kang grew up and attended school in Hong Kong and could recall some of his childhood experiences. He had been to Beijing in 2010 and has also returned to Hong Kong in the last 10 years. Kang stated that "he was hoping to have no expectations" about what this experience might offer. The lead author, who was their faculty advisor, believed that all three students were generally positive individuals who interacted well with their peers.

\section{Procedure}

Preservice music education student teachers were selected through a purposive recruitment process and were interviewed individually by their faculty advisor, using a semi-structured protocol while in China (see Appendix). These Canadian students were a part of a SSHRC funded Canada-China Reciprocal Learning Program and also received financial support from Mitacs, a national organization that supports research between Canada and select countries. These preservice music teachers lived in China for three months and resided at Southwest University in Chongqing. They were asked to keep daily notes and reflections relating to the many classes that they observed, the lectures and workshops that they attended or participated in and their own self-analysis of their personal and professional growth. Debriefing sessions were arranged on a regular basis by three faculty advisors who accompanied the students during their three-month stay in China. This gave the Canadian students the opportunity of express any concerns that arose on a weekly basis and to share their own learning experiences with faculty and their peers. While the purpose of these debriefings was not to generate date, it did give students an opportunity to formulate their thoughts and express concerns in a public and safe setting. Also, the principal investigator (lead author) was the faculty advisor for the student participants, traveled to China with them, and accompanied them as they went about their daily routine (e.g., lived in the same dormitory as the participants, attended classes and workshops with the participants, and spent considerable personal time with them). This arrangement allowed for close observation of the student teachers on a daily basis. 
The participants were interviewed during the last week of their three-month residency. For this reason, they were in an ideal position to reflect on their residency and to offer informed advice to prospective future exchange students in the Reciprocal Learning Program. They responded to a series of open-ended questions, which were grouped thematically or by topic. Topics addressed during the interviews related to their early preconceptions of life in China, their coping strategies (e.g., language, local customs, environmental context) while in this foreign land, the curricular and pedagogical similarities and differences they experienced during their school visits, the nature of their relationships with their Chinese counterpart (buddy), and the possible impact this once-in-alifetime experience might have on their future educational and professional plans. The interviews were recorded with a digital voice recorder and the audio data were transcribed before they were analyzed. Each interview lasted approximately two hours and took place in a location of the participants' choosing (e.g., international student residence, coffee shop, and restaurant). Participants chose or approved of the pseudonyms that were used, thus assuring confidentiality. Data analysis was an iterative process where the researchers extracted from the acquired interview data key ideas and perspectives, which in turn were further distilled, until the final summary encapsulated all essential elements of the original transcribed interviews (Bayley \& Waldron, 2019).

\section{Findings and Discussion}

The participants were asked a series of open-ended questions relating to their preconceived understanding of China, their experiences during this three-month residency, and how this personal and educational international experience might impact their future pedagogy as beginning music teachers. Each of the participants' statements was a result of their own evolving value system and what they eventually took away from the experience as being personally meaningful. The results follow the structural design of the interview protocol.

To begin the interview process and put the students at ease, the participants were asked, how would you describe your overall experience in the reciprocal learning program to date? All participants valued greatly the opportunity to come to China. Cello spoke of this opportunity as "a definite valuable learning experience culturally, socially, and educationally." She indicated that this experience helped her to understand "more about [herself] in general" (e.g., interactions with people, limitations, etc.). After some thought she stated, "so I guess in a way I have matured," indicating that as a result of this new experience she was possibly more self-reflective. For her, China was "physically, mentally, and emotionally quite draining." Both Kang and Bryce believe that the program requires having an open mind. Bryce described his overall experience as "mind opening...It's giving me a different perspective in how I would treat students in the classroom." Consequently, he has since given more thought to the notion of differentiation as it relates to teaching and learning.

In addition to the overall experience, participants shared their expectations prior to arriving in China. Cello said she had an impression of "mainlanders" as being loud and rude. She claimed, "my mother did tell me before, if you need to get something in Beijing, you need to speak very loud...in a sense where you feel like you're being rude, but they won't take it that way." She confessed that she was "a bit skeptical" of what she might experience prior to her arrival in China. Bryce was focused on what he might get out of this experience, stating: 
I was looking to have an experience where I was out of my comfort zone. I wasn't exactly sure what it was really going to mean to be here. I just knew it was a place that was far away from home.

Kang did not realize to what degree language would prove to be such a challenge for him. He naively stated that he thought he would "pick up, more, or understand more." He further explained,

I thought, okay...I [am] going to understand, I [am] going to take notes...I am going to know what they are talking about. But as soon as I walked into that first lecture, I was like, oh [no], everything is in Chinese.

His understanding of his preschool experience in Hong Kong may have given him a false sense of confidence.

Along with their expectations, participants were asked if their pre-arrival perceptions changed as a result of their lived experiences in China and, if so, what precipitated the change. Cello admitted that she watched a number of documentaries about China before travelling but stated that it was "a bad idea." Her attitude did change as a result of experiencing how her Chinese associate teacher taught and interacted with his students. She was amazed how teachers accomplished so much in such a short period of time. She stated, "I knew they would be efficient, but I didn't realize they would be this efficient." Knowing what he knew now, Bryce claimed that he would have involved himself more in the Fall term when students from Southwest University arrived in Windsor, Ontario, for their three-month residency. He was very pleased that he could be somewhat self-sufficient even under unusual conditions (e.g., ordering food, transportation, etc.). "Mass uncertainty" changed his perspective. However, he also admitted, "It's also the thing I'm most thankful for." Kang indicated that, as a result of his residency in mainland China, he was encouraged to include more "activities" as a part of his classroom presentations or teaching because Chinese students "are more used to lectures." He believed that being in China for three months, instead of just one month, helped him to "really get to know people."

In an effort to focus participants' self-reflections, the researchers asked them what they considered to be the most memorable experience to date. Cello was a very accomplished cellist and a physically active individual. It was not a surprise that these two integral components of her personal makeup were something she yearned for when away from home. She stated that she was not very content living in this new land until she was introduced to a dance studio (Dance House Academy) in Chongqing and when she was able to borrow a cello. It was a stabilizing factor for her. Without her cello she "felt psychologically very negative all the time." She stated that when she engaged in these activities, "it was more bearable for me." Bryce reflected on the novelty of being in China and coping with the unfamiliar. He specifically mentioned the experience of teaching at an unfamiliar grade level (Grade 3) and out of his subject area (music). Arriving in Beijing was another memorable experience. When he first saw the Summer Palace he said, "I'm in China. This is so strange." Kang spoke fondly of the opportunity he had to play pick-up basketball with the Chinese students. He stated that "getting to work with the kids" was his most memorable experience in China.

When asked about various challenges and coping strategies, the participants offered a wide range of responses depending on their individual personalities and past experiences. Cello, a very structured individual, indicated that when she was back home in Canada she always "planned her day by the hour." Social behaviours and environments posed ongoing challenges for her, such as the adjustment to the spicy, oily food (e.g., Chongqing hot pot) and day-to-day living conditions. 
Also, she frequently encountered frustration with local Chinese. When she informed them that she did not speak Mandarin, they would say to her, "[you're] so cute, and you're trying so hard." Cello stated that in order to cope with these challenges, she could "pick up decently well" the body language of the Chinese with whom she interacted. For Bryce, the timing of the trip made it difficult for him to properly engage back home with the job market or to upgrade (e.g., take Additional Qualification courses). In addition to not being able to fully prepare himself for future employment, he struggled with not being able to communicate competently with those he interacted with on a daily basis. He stated,

The language barrier has been one of the biggest challenges as well. I can't walk into a restaurant and feel comfortable ordering food. I mean, it's self-imposed doom, because I'm a vegetarian. If I wasn't, I could just go and point and I would be fine, you know.

Bryce prepared in advance for the inevitable and made good use of technology, stating, "Generally, I stick with the familiar more often than I'd like to... and I try to be very prepared in advance...I have my translator app ready...I have listened to the words over and over in my head." Bryce, in an attempt to have control in his new environment, brought his guitar, thus making it possible to participate in music activities (at least with his peers) when he so wished. Kang also stated that his two greatest challenges were language and food, despite his previous limited experiences in China. He believed that language was the foremost challenge, despite the fact that he "understood numbers fine." He also indicated that he found it difficult to adapt to not having "some breathing room to do other things" and the fact that the schedule differed from what they were given prior to their travel. Kang, like Cello, attempted to borrow a Euphonium (his primary instrument) while in China. However, despite numerous attempts to acquire an instrument, he was informed that this would not be possible.

The Canadian students offered insightful suggestions as to how the Reciprocal Learning Program could better prepare them to cope with the challenge of language in advance of their foreign residency. Participants believed that the brief language drills during pre-trip meetings were for the most part ineffective. They thought a translation app could prove helpful and knowing more practical phrases would be more beneficial (e.g., laundry, washroom, vegetables, animal names [chicken, pork, beef, fish], etc.). Because Google technologies are restricted in China, the Canadian students were not able to access Google translator.

Cello stated emphatically that it was very important to "have thick skin and have a very open mind... because the Chinese here, some of them don't realize that what they say is extremely rude in our context." Bryce, on the other hand, offered practical advice stating, "don't over prepare...some of the magic of being over here is the surprise." As a means of easing some of the inevitable anxiety, he suggested providing students with a list of websites on China for them to study prior to traveling and to begin the Mitacs grant application process earlier. Kang offered a wide range of suggestions for future travelers. He stated that is it is important to give careful thought to "packing the right things" (e.g., mosquito repellent) and go with "an open mind." With respect to preparing the Mitacs grant application, he suggested that students take into consideration the language barrier as well as the Chinese curriculum and educational setting (e.g., limited instrumental music). Increased awareness of these details could potentially help students align their proposals more realistically with cultural and educational norms in China.

During the three months the preservice students were in China, they stayed in an international dormitory on the campus of Southwest University. Their daily routine often meant that they would eat together, travel together, and attend workshops or present to Chinese students 
and teachers as a group. This did not always result in smooth relationships as sometimes witnessed by students and faculty advisors. When asked, what contributes to successful relationships with peers? the participants offered valuable advice for their future counterparts. Cello stated emphatically, "Honesty." She went on to say that "in any relationship, honesty is like a foundation of trust." She remembered a saying on a poster from her early days in a music program in Canada: "your thoughts become your words, your words become your actions, actions become habits, and habits become your character...Things come back you know. Karma, she is a very persistent and very strict lady." Bryce, an outgoing and mature individual, identified specific personality traits as being important for maintaining a successful relationship with one's peers: "being nice, being generous...My general philosophy is to try to do as much for others as you can, and you're going to be more satisfied with yourself... Try not to gossip." He stated that it is especially important to "be willing to try things" and "try not to say 'no' over here." In the spirit of adventurism, he claimed, "I'm interested in every opportunity you are going be provide me with." Kang stated that being humble was an important characteristic to have when building a relationship with peers, stating, "don't pretend to know everything." He also suggested that being willing to be with people to socialize was important for building good relations with the Chinese "buddies." Many of the students' philosophical perspectives were formed as a result of interactions they had with various individuals (e.g., students, faculty, and day-to-day acquaintances) while in China.

In addition to the importance of peer relationships (both Canadian and Chinese), the participants shared their perceptions of the required classroom observations and teaching opportunities while in China. A large part of the participants' day was spent attending classes and observing Chinese teachers giving instruction in a variety of subject areas (e.g., art, chemistry, math, physical education, and music). In terms of preparation for these school visits, the participants indicated that observation strategies and techniques were never officially discussed prior to leaving Canada. Given the extended time Canadian students had observing teaching in China, it may have proved beneficial to have specific instruction in observation techniques prior to departure (Seidman, 2013). Regarding their daily routine of school visits, students were asked, which class observations have been the most beneficial to you as a future teacher and why? Cello stated the following:

The first English class left quite an impression on me because, even though Thomas, my [Chinese] associate teacher was very strict...[there was] no time for distractions. It was just so productive....and the kids were so disciplined. He got through so much material within forty minutes.

By contrast, Bryce stated in his Mitacs grant application that he was interested in observing how the teachers taught music. However, he was disappointed that he did not get to see very much music being taught within the high school setting. This may have been due to predetermined program scheduling, where the primary focus was on "core" subjects with limited music instruction at this level of schooling. Kang stated that he was relieved when he did not have communication problems/challenges and instruction was somewhat less directed. He claimed that "observing the English class was the biggest one, just because I understood exactly what was going on. Whereas the other classes, it was PowerPoint, lecture, lecture, lecture, lecture, lecture in the class." The participants agreed that the least beneficial aspect of their time in China was the daily observations (duration and frequency during much of their residency). This, combined with the language barrier, often contributed to boredom and frustration. The Canadian students' interaction with the Chinese teachers was very limited and at no time did it resemble a debriefing of lessons 
previously observed. Consequently, this was a missed opportunity to engage in reciprocal learning. This could have been as a result of not planning for mutual sharing, the differences in professional status, and/or the inability of both parties to meaningfully communicate in either English or Chinese.

Prior to traveling to China, the Canadian students attended Skype meetings with their faculty and student counterparts from Southwest University in Chongqing. They believed that this way of interacting with high schools via Skype had proven to be some of the least productive pretravel requirements. The Skype meetings were scheduled very early in the morning (7:00 am Eastern) to accommodate the Chinese teachers, students, and faculty, and often consisted of presenting reports with little or no reference to the participants' primary subject area (music). This scheduled pre-trip activity appeared to be an attempt at reciprocal learning but, according to the student teachers, fell short of potential goals.

All three participants were music education majors in a Faculty of Education. In addition to their pre-travel and observation frustrations, all of the participants agreed that their time could have been better used teaching music classes while in China, as this study-abroad program replaced their practicum at their home university. At times, there appeared to be some hesitation to allow Western preservice students to teach a class. This could have been a result of their social position or the possibility of deviating from Chinese national curriculum standards. With regards to the music classes, Bryce stated that his experience was "overall...positive" and explained that he was impressed with the students' abilities. By contrast, both Kang and Cello spoke negatively about the music classes. Kang claimed that they were "too rigid" with "no sense of freedom" as the students had to learn "exactly what was in the text." Similarly, Cello summed up her frustration with gaining access to music classes in one word: "lacking." During her three-month stay in China she had little opportunity to experience music teaching in the schools. She added, "I actually had to go out of my way to ask many music students to see if they could let me in on pipa classes or guzheng classes." Cello expressed some degree of frustration when she added, "when I was there, I was only teaching English. I was teaching an English class and I'm a music teacher, right?" It is very likely that the Chinese teachers did not know of the Canadian student teachers' subject area. When a music teacher realized Cello was a music major, she gave her 10 minutes to teach students a song. She reflected, "I thought, well, 10 minutes is better than nothing." In addition, the participants also came to the realization that their intended educational investigations as outlined in their Mitacs applications could not fully be realized, and opportunities to observe and teach instrumental music classes were few or non-existent. Possibly, acquiring a greater awareness of Chinese curricular requirements and priorities before leaving their home country would help the student teachers design more realistic applications for Mitacs. In addition to the limited opportunities to teach Chinese children, the Canadian preservice student teachers were given the opportunity to give a presentation to a large group of high school students. Topics varied from "life in Canada" to "Canadian music artists."

When asked to identify similarities or differences to their Canadian music classes, participants noted that, as is the case in many Canadian elementary schools, solfège was used as a pedagogical tool to help students match pitch and sing the required songs. Participants described classroom instruction as being primarily teacher centered/driven, which was a particular concern for Kang. The participants noted that in music class, Chinese students decoded a number system (movable do) when reading music. This was the case in the elementary music classes and the instrumental (orchestral) classes, which were comprised of both traditional Chinese and Western instruments (e.g., pipa, cello). None of the participants indicated that this pedagogical notational practice was something that they might incorporate into their in-service teaching in the future. 
Participants noted in their observations that no Western music was performed or heard, but Chinese "folk" music was sung in unison.

In addition to the pedagogical challenges, the participants were soon facing the reality of joining the teaching profession. When asked how the Chinese reciprocal experience might impact their future teaching pedagogy, the participants had unique perspectives. Cello stated that she was going to encourage students to ask questions but not to "lose face." This statement came about as a result of her classroom observations and her acute awareness of the feelings of others. Bryce stated that he would be more focused in his teaching, where he would be more sensitive (empathetic) to English as a second language (ESL) learners. "I believe I'm a profoundly different teacher now than when I left [Canada]." Kang reflected on some of his perceived negative experiences while in China and stated that he learned "what not to do" in his own teaching. In the future he would try and not lecture too much and use visuals in his lessons, which he thought would help ESL students.

Along with the overall effect on the participants' future teaching, they shared their perceptions of trip duration and the impact of their extended stay in China. Previous university student trips to China had been for a duration of approximately one month. The students that were interviewed for the present study were the first group to be a part of a three-month residency. This extended period of time was made possible because of the Mitacs grant that each student received. It was evident from student responses that duration made a difference, as it takes time to become acclimated to the cultural and physical context, to meaningfully build friendships, and to learn the ways of others. The participants identified advantages and disadvantages of having an extended stay. Cello preferred the three-month duration, claiming, "you build thicker skin and...[learn] to care less about things. One month is not enough to adapt to the culture and get the full experience." She honestly added, "you can only be with certain people for so long." She suggested that one month was not enough, "two months would be good," three months, "it's time to go home." In a similar fashion, Kang spoke of developing a sense of community and a sense of belonging. He indicated that, as a result of being in China for three months, he was able to befriend local shopkeepers, who in turn learned a few English expressions (e.g., "good night, hey man, how are you, good night, and bye"). As a result of his stay, he was able to "blend in with the community and get to know the community." It is possible that such an extended stay provided the participants enough time to abandon the tourist role and to take on the persona of someone residing in China.

As a concluding question, preservice students were asked, what will you miss most about leaving China? Each student identified something different but yet important to him or her; a final thought as it were. Cello identified three things that stood out for her, stating, "I really like the cheap food, the fact that the children are so disciplined, and maybe the fact that I can haggle the prices here." Both Bryce and Kang spoke in general terms of what they perceived to be informal reciprocal encounters. Bryce focused on what he believed were unique cultural expressions, claiming, "I will miss the sense of collective culture here together of people going out and running at night together, singing and music everywhere." On a personal level, Kang stated that he would miss "the people, the relationships that [I] buil[t], and the buddies, realizing that $[\mathrm{I}]$ might never, ever see them again." Given their time in China, the connections they made with school children, undergraduate university students at Southwest University (buddies), as well as the people they met as a part of their daily routine, the Canadian students were asked, do you think you might ever return to China? Although Cello's grandparents live in China, she was very emphatic when she said, "two weeks at most." Bryce said "yes." He hoped to return to both China and Thailand. He stated, "I realized the world is a big place. I need to see a lot of it. I can have these experiences in a lot of places." When speaking of the effect his stay in China had on him, Kang stated, "yes, when 
you come here for three months and establish relationships, that changes things." To some degree, this was true for all participants, regardless of previous background, individual maturity, subject area expertise, or age.

\section{Limitations}

These findings reflect the beliefs and perspectives of a very limited number of students in a relatively controlled environment. However, many of the statements of the participants align with that of the lead researcher's observations during numerous visits to China. As is often the case with drawing conclusions from case study research, it is not always possible to arrive at conclusions that represent the perspectives of all participants. While all three participants were individuals in their own right, they often perceived their reality differently, interacted with their student peers (buddies) and Chinese locals in unique ways, and drew meaning from their time in China based on their own personal lived experiences. The present exploratory investigation focused on the personal and professional experiences of preservice Canadian music education students during a three-month residency in China. Future research might continue the investigation to determine if this unique educational experience had any impact on their approach to teaching in the future.

\section{Conclusions}

The conceptual framework for this study draws upon the literature relating to international education, study-abroad programs, and reciprocal learning in teacher education. According to Xu and Connelly (2018), "Reciprocal Learning as Collaborative Partnership (RLCP) holds that people of different cultures negotiate shared meaning. Meaning is not defined in advance. Meaning is shared in actions, not words." The Canadian preservice students were very eager to express their thoughts and ideas relating to the international opportunity they experienced. They were generous with their time, gave the impression that they were truly supportive of this international reciprocal program, and were keen to offer advice that might improve the experience for future students.

The principal investigator perceived that some change had taken place as a result of the various interactions that the students had with their peers, Chinese buddies, and faculty. All preservice music students made social and psychological adjustments while in China so as to personally benefit from this unique experience. This involved adjusting preconceived attitudes and expectations, maintaining a sense of adventure and engaging in various forms of self-reflection (e.g., debriefing sessions, personal journals, and personal conversations with peers). This aligns with Robertson and Webber's (2000) contention that these are an essential part of the international experience. Two of the students were Canadian-Chinese and consequently Chinese locals often expected more of them, especially in terms of language. However, all participants experienced significant challenges relating to the local food and language (Zhao et al., 2009). Frustration was also expressed with the few opportunities that students had to observe, teach, or perform music during their three-month residency in China.

The findings suggest intellectual, social, and personal growth over this three-month period. Students spoke of overcoming the "fear of the unknown" and acquiring greater self-awareness. While all participants suggested that this experience impacted their life, there was no solid evidence to show that their experiences would have an effect (positive or negative) on future pedagogical practices as teachers. Therefore, it is logical to suggest that further research, as to what impact such international education opportunities might have on the pedagogical practices of 
preservice teachers, is warranted. This investigation of lived experiences provides academics, students, and administrators with constructive insights into the educational and personal growth of undergraduate education students, who have successfully negotiated the unfamiliar, adapted to the strange, and in turn have been enriched by a culture other than their own.

\section{References}

Bayley, J. G., \& Waldron, J. (2019). It's never too late: Adult students and music learning in one online and offline convergent community music school. International Journal of Music Education, 38(1), 36-51. https://https://doi.org/10.1177/0255761419861441

Biddle, J. (2010). Reciprocal learning in leadership. ReSource, 29(1), 17-19.

Boud, D. (1999). Situating academic development in professional work: Using peer learning. International Journal for Academic Development, 4(1), 3-10. https://doi.org/10.1080/1360144990040102

Brindley, R., Quinn, S., \& Morton, M. (2008). Consonance and dissonance in a study abroad program as a catalyst for professional development of pre-service teachers. Teaching and Teacher Education, 25(3), 525-532. https://doi.org/10.1016/j.tate.2008.09.012

Government of Canada. (2019). Canada-China relations. Retrieved from https://www.canadainternational.gc.ca/china-chine/bilateral_relations_bilaterales/index.aspx ?lang=eng

Carson, J., \& Longhini, A. (2002). Focusing on learning styles and strategies: A diary study in an immersion setting. Language Learning, 52(2), 401-438. https://doi.org/10.1111/0023-8333.00188

Charmaz, K. (2006). Constructing grounded theory: A practical guide through qualitative analysis. Thousand Oaks, CA: Sage.

Creswell, J. W. (2013). Qualitative inquiry and research design: Choosing among five approaches (3rd ed.). Thousand Oaks, CA: Sage.

Cushner, K. (2007). The role of experience in the making of internationally-minded teachers. Teacher Education Quarterly, 34(1), 27-39.

Cushner, K., \& Mahon, J. (2002). Overseas student teaching: Affecting personal, professional, and global competencies in an age of globalization. Journal of Studies in International Education, 6(1), 44-58. https://doi.org/10.1177/1028315302006001004

Dessoff, A. (2006). Who's not going abroad? International Educator, 15(2), 20-27.

Dunn, A., Dotson, E., Cross, S., Kesner, J., \& Lundahl, B. (2014). Reconsidering the local after a transformative global experience: A comparison of two study abroad programs for preservice teachers. Action in Teacher Education, 36(4), 283-304. https://doi.org/10.1080/01626620.2014.948227

Faulconer, T. (2003, April). These kids are so bright! Pre-service teacher's insights and discoveries during a three-week student teaching practicum in Mexico. Paper presented at the 2003 annual meeting of the American Educational Research Association, Chicago, IL.

Gay, G. (2002). Preparing for culturally responsive teaching. Journal of Teacher Education, 53(2), 106116. https://doi.org/10.1177/0022487102053002003

Hoy, W., \& Miskel, C. (2005). Educational administration: Theory, research and practice. New York, NY: McGraw Hill. 
Jones, M. (2005). Fitting in, feeling excluded or opting out? An investigation into the socialization process of newcomers into the teaching profession in secondary schools in England. Journal of InService Education, 31(3), 509-526. https://doi.org/10.1080/13674580500200291

Kabilan, M. K. (2013). A phenomenological study of an international teaching practicum: Preservice teachers' experiences of professional development. Teaching and Teacher Education, 36, 198-209. https://doi.org/10.1016/j.tate.2013.07.013

Ladson-Billings, G. (1995). But that's just good teaching! The case for culturally relevant pedagogy. Theory Into Practice, 34(3), 159-165. https://doi.org/10.1080/00405849509543675

Lambert, L. (2002). Introduction. In L. Lambert, D. Walker, D. Zimmerman, J. Cooper, M. Lambert, M. Gardner, \& M. Szabo (Eds.). The constructivist leader (pp. xv-1), New York, NY: Teachers College Press.

Malewski, E., \& Phillion, J. (2009). International field experiences: The impact of class, gender and race on the perceptions and experiences of preservice teachers. Teaching and Teacher Education, 25(1), 52-60. https://doi.org/10.1016/j.tate.2008.06.007

Marx, H., \& Moss, D. (2011). Please mind the culture gap: Intercultural development during a teacher education study abroad program. Journal of Teacher Education, 62(1), 35-47. https://doi.org/10.1177\%2F0022487110381998

Mendelson, V., \& Citron, J. (2006). Bringing it home: Multifaceted support for returning education abroad students. International Educator, 15(3), 64-67.

Merryfield, M. M. (2000). Why aren't American teachers being prepared to teach for diversity, equity, and interconnectedness? A study of lived experiences in the making of multicultural and global educators. Teaching and Teacher Education, 16(4), 429-443. https://doi.org/10.1016/S0742051X(00)00004-4

Nieto, J. (2006). Cultural plunge: Cultural immersion as a means of promoting self-awareness and cultural sensitivity among student teachers. Teacher Education Quarterly, 33(1), 75-84.

Norris, E. M., \& Dwyer, M. M. (2005). Testing assumptions: The impact of two study abroad program models. Frontiers: The Interdisciplinary Journal of Study Abroad, 11, 121-142. https://doi.org/10.36366/frontiers.v11i1.154

Norris, E. M., \& Gillespie, J. (2009). How study abroad shapes global careers. Journal of Studies in International Education, 13(3), 382-397. https://doi.org/10.1177\%2F1028315308319740

Pence, H. M., \& Macgillivray, I. K. (2008). The impact of an international field experience on preservice teachers. Teaching and Teacher Education, 24(1), 14-25. https://doi.org/10.1016/j.tate.2007.01.003

Phillion, J., Malewski, E. L., Sharma, S., \& Wang, Y. (2009). Reimagining the curriculum: Future teachers and study abroad. Frontiers: The Interdisciplinary Journal of Study Abroad, 18(1), 323-339. https://doi.org/10.36366/frontiers.v18il.269

Powell, K. (2006). Educational psychology of the self: An interactive workbook. Dubuque, IA: Kendall Hunt.

Powell, K. C., \& Kalina, C. J. (2009). Cognitive and social constructivism: Developing tools for an effective classroom. Education, 130(2), 241-250.

Robertson, J. M., \& Webber, C. F. (2000). Cross-cultural leadership development. International Journal of Leadership in Education, 3(4), 315-330. https://doi.org/10.1080/136031200750035950

Sahin, M. (2008). Cross-cultural experience in preservice teacher education. Teaching and Teacher Education, 24(7), 1777-1790. https://doi.org/10.1016/j.tate.2008.02.006

Sefton, T., Rideout, G., \& Bayley, J. G. (2016). Collaborating in (mis)translation: Opportunities lost and found during a multi-year exchange program between Canada and China. Comparative and International Education, 45(3), Article 3. 
Segalowitz, N., \& Freed, B. F. (2004). Context, contact, and cognition in oral fluency acquisition. Studies in Second Language Acquisition, 26(2), 173-199. https://doi.org/10.1017/S0272263104262027

Seidman, I. (2013). Interviewing as qualitative research (4th ed.). New York, NY: Teachers College Press.

Stachowski, L. L., \& Sparks, T. (2007). Thirty years and 2000 student teachers later: An overseas student teaching project that is popular, successful and replicable. Teacher Education Quarterly, 34(1), 115132.

Stachowski, L. L., Richardson, J. W., \& Henderson, M. (2003). Student teachers report on the influence of cultural values on classroom practice and community involvement: Perspectives from the Navajo reservation and from abroad. The Teacher Educator, 39(1), 52-63. https://doi.org/10.1080/08878730309555329

Stake, R. E. (2005). Qualitative case studies. In N. K. Denzin \& Y. S. Lincoln (Eds.), SAGE handbook of qualitative research (3rd ed., pp. 443-466). Thousand Oaks, CA: Sage.

Thomas, P. G. (2006). Pre-service practicum teaching in central Asia: A positive experience for both worlds. Journal of Social Studies Research, 30(1), 21-25.

Trilokekar, R. D., \& Kukar, P. (2011). Disorienting experiences during study abroad: Reflections of preservice teacher candidates. Teaching and Teacher Education, 27(7), 1141-1150. https://doi.org/10.1016/j.tate.2011.06.002

Van Swet, J., \& Ponte, P. (2007). Reciprocal learning by experienced teachers and their educators on a master's degree programme in The Netherlands. Journal of In-Service Education, 33(1), 67-90. https://doi.org/10.1080/13674580601157711

Volet, S. E., \& Ang, G. (2012). Culturally mixed groups on international campuses: An opportunity for inter-cultural learning. Higher Education Research and Development, 31(1), 21-37. https://doi.org/10.1080/07294360.2012.642838

Vygotsky, L. S. (1978). Mind in society. Cambridge, MA: Harvard University Press.

Willard-Holt, C. (2001). The impact of a short-term international experience for preservice teachers. Teaching and Teacher Education, 17(4), 505-517. https://doi.org/10.1016/S0742-051X(01)00009-9

Xu, S. J., \& Connelly, F. M. (2017). Reciprocal learning between Canada and China in teacher education and school education: Partnership studies of practice in cultural context. Frontiers of Education in China, 12(2), 35-150. https://doi.org/10.1007/s11516-017-0013-6

Xu, S. J., \& Connelly, F. M. (2018, May). Partnership, theory, practice, and method: Accomplishment questions, and the future. Paper presented at the fifth annual International Conference on Reciprocal Learning Between Eastern and Western Education, Northeast Normal University, Changchun, China.

Zhao, Y. (2007). Impact of immersion experience in an immigrant community on pre-service teachers' cross-cultural and global awareness. Education and Human Development, 1(2), 1-10.

Zhao, Y., Meyers, L., \& Meyers, B. (2009). Cross-cultural immersion in China: Preparing pre-service elementary teachers to work with diverse student populations in the United States. Asia-Pacific Journal of Teacher Education, 37(3), 295-317. https://doi.org/10.1080/13598660903058925

\section{ЛL}




\section{Appendix}

Interview Questions (Preservice Music Students)

The overall experience (Prelude):

Q: How would you describe your overall experience in the reciprocal learning program to date?

Perspectives (an evolution):

I want you to think of what you were thinking your experience would be in China before you arrived. In other words, what did you think your experience would be like?

Q: Have your before and after perceptions changed as a result of your lived experiences over the last ten weeks?

Q: [If you experienced a change of perspective], what do you think influenced this change?

Q: What would you say is your most memorable experience to date?

Q: What challenges did you experience as a result of taking this journey (literally/figuratively)?

Hindsight:

Q: What advice would you offer prospective students who are planning to participate in the Reciprocal Learning Program?

\section{Daily Activities:}

Peer relationships -

Q: What contributes to a successful relationship with your peers ( $\mathrm{U}$ of W students)? In other words, what makes for a happy/successful working relationship among your peers?

Q: Describe your relationship with your SWU buddies. What contributes to a successful relationship with your SWU buddy?

This is the first year that the RLP has included graduate students.

Q: Has this made a difference? In other words, what have the graduate students brought to this experience?

School visits - class observation:

Q: Were you given any guidance on the appropriate protocol/technique/strategies for observing a class?

Q: What classes have you observed to date?

Q: How would you describe your daily routine?

Q: Which class observations have been the most beneficial to you as a future teacher? Why?

Q: What has been the least beneficial? Why?

Your role as observer:

Your role was primarily one of an observer.

Q: What aspects of classroom observation would you change if you could?

Q: Do you think your role (that of observer) should be changed (enhanced)? In other words, do you believe you should be doing more than observing on a daily basis?

Q: If yes, what would this changed (enhanced) role look like? In other words, what else could you be doing?

Q: Would it be beneficial if you had an interpreter with you as you visit classes? 
Q: Would it be beneficial if you could have some time to debrief with the teacher prior or after a lesson?

Q: What would be the advantages be (for you and the students) if you had a more engaging/active role in the classes?

Music classes:

Q: How would you describe your overall experiences in the music classes you observed?

Q: What similarities to Western music classes did you witness during your observations?

Q: What differences to Western music classes did you witness during your observations?

Q: Should there be more opportunities for $U$ of W students to teach classes? What classes would be appropriate?

Q: Would it be more beneficial if you were to spend more time observing your subject area (e.g., music)?

Q: Were there any aspects of the music classes you observed that had elements of Western influence (e.g., music/repertoire, solfège)?

Language (Coping Strategies):

Q: How many words do you think you know in Chinese?

Q: How did you cope (strategies) when dealing with the language barrier?

Q: What was one incident that involved miscommunication or no communication?

Q: How might the program assist $\mathrm{U}$ of $\mathrm{W}$ students with learning the Chinese language? Q:

Should there be a greater emphasis on language acquisition?

Q: What (how much) should we tell students before they come to China

Change over time:

Q: Do you think this educational experience might influence your teaching (pedagogy), in the spirit of reciprocal learning? In what way might this experience influence your future teaching?

Trip Duration:

Previous student trips to China have been one month in duration. This present stay is three months.

Q: Has your perspective and knowledge changed since the end of the first month? In other words, have things changed for you because of the extended stay?

Q: What do you think are the advantages/disadvantages of having a three-month residency?

Final Thoughts:

Q: What will you miss most about leaving China?

Q: Do you think you might ever return to China?

Q: How might we encourage RLP alumni to continue to be involved after their residency?

Q: Is there anything else you would like to say regarding your experiences in the Reciprocal learning Program? 